\title{
A nova família e a ordem jurídica*
}

\author{
Maria Lygia Quartim de Moraes**
}

\section{Resumo}

O livro A Família em Desordem, da historiadora e psicanalista Elizabeth Roudinesco, constitui uma das mais positivas contribuições para o estudo das famílias no mundo contemporâneo. A tese da autora é de que não obstante todas as "desordens", que vão da perda do poder paterno aos casais homossexuais, a instituição familiar vem sobrevivendo mais bem do que mal. Segundo ela, a família é atualmente reivindicada como o "único valor seguro ao qual ninguém quer renunciar", independentemente da idade, sexo, orientações sexuais ou classe social. Esse anseio pela família leva com que os rearranjos, frutos da "família em desordem" demandem por novos direitos que alteram os pressupostos tradicionais sobre o tema.

Palavras-chave: Famílias Contemporâneas, Práticas Jurídicas.

\footnotetext{
Recebido para publicação em 12 de setembro de 2010, aceito em 27 de fevereiro de 2011. Trabalho apresentado na $27^{a}$. Reunião Brasileira de Antropologia, realizada entre 01 e 04 de agosto de 2010, Belém, Pará, Brasil.

** Professora do Departamento de Sociologia do IFCH e pesquisadora colaboradora do Núcleo de Estudos de Gênero - Pagu, ambos na Unicamp. maria_quartim@uol.com.br
}

cadernos pagu (37), julho-dezembro de 2011:407-425. 
A nova família e a ordem jurídica

The New Family and the Legal Order

\begin{abstract}
The Family in Disorder, written by historian and psychoanalyst Elizabeth Roudinesco, is one of the most positive contributions to the study of the families in the contemporary world. The author's thesis is that despite all the "disorder", ranging from the loss of paternal power and homosexual couples, the institution of the family is surviving. According to her, the family is being claimed as the "single value insurance to which nobody wants to renounce", regardless of age, sex, sexual orientation or social class. This yearning for the family brings with it rearrangements, resultant of the "family in disorder", and new rights that challenge the traditional assumptions about the theme.
\end{abstract}

Key Words: Contemporary Family, Family Jurisprudence. 


\section{As famílias em desordem e a ordem jurídica.}

...para os pessimistas que pensam que a civilização corre o risco de ser engolida por clones, bárbaros bissexuais ou delinquentes da periferia, concebidos por pais desvairados e mães errantes, observamos que essas desordens não são novas - mesmo que se manifestem de maneira inédita -, $e$ sobretudo que não impedem que a família seja atualmente reivindicada como o único valor seguro ao qual ninguém quer renunciar. Ela é amada, sonhada e desejada por homens, mulheres e crianças de todas as idades, de todas as orientações sexuais e de todas as condições (Roudinesco, 2003:198).

O livro A Família em Desordem, da historiadora e psicanalista Elizabeth Roudinesco constitui uma das mais positivas contribuições para o debate e para o estudo das famílias no mundo contemporâneo. A tese da autora é de que não obstante todas as "desordens", que vão da perda do poder paterno aos casais homossexuais, a instituição familiar vem sobrevivendo mais bem do que mal. Concordando com suas palavras, analiso algumas circunstâncias $e$ as dimensões das inúmeras transformações sofridas pelo Direito de Família, tanto no que diz respeito às suas normas, quanto no que se refere à jurisprudência. ${ }^{1}$

No Brasil, essas mudanças são fruto de um conjunto de fatores entre os quais se destacam a industrialização, a expansão do mercado consumidor, a incorporação da mulher à esfera do trabalho remunerado, o avanço nas técnicas de controle da natalidade e o movimento feminista. Assim, novas formas de convivência conjugal e realidades familiares antecederam a incorporação constitucional que reconhece e legitima relações $e$

${ }^{1}$ Este texto apoia-se em resultados preliminares da pesquisa Direito de família: teorias e práticas contemporâneas, que venho desenvolvendo com o apoio do CNPq. 
A nova família e a ordem jurídica

famílias existentes de fato. Essa constatação exige um breve registro histórico para situarmos melhor as conquistas consagradas na Constituição Federal de 1988, fruto da democrática Constituinte que redefiniu o país legal após mais de duas décadas de ditadura militar.

$\mathrm{Na}$ verdade, em apenas nove incisos, o artigo 226 da Constituição Federal - CF de $1988^{2}$ desmontou toda a armadura legal de um sistema de desigualdades entre homens e mulheres, consagrado pelos preconceitos seculares do Código Civil de 1916. Esse, por sua vez, apoiava-se inteiramente no Direito Canônico que instituía o casamento como único meio de se constituir uma família. Nesse sentido, o Código de 1916 estabelecia caber ao marido a "chefia", vale dizer, administração dos bens, manutenção material da família, direito de fixar residência, enquanto à mulher era outorgada a função de ser a "companheira, consorte e colaboradora" do chefe da família, "cumprindo-lhe velar pela direção material e moral desta" (Art. 233 e 240).

A família que aparece na CF 1988 fundamenta-se no princípio da igualdade entre homens e mulheres e é descrita como "base da sociedade" a quem o Estado garante proteção. Nessa nova família, ambos os cônjuges exercem igualmente "os direitos e os deveres referentes à entidade familiar", prevalece o princípio constitucional da igualdade jurídica entre todos os filhos, nascidos ou não no casamento, naturais ou adotados, e a redução dos prazos e das exigências para o divórcio. Finalmente, o preceito legal de família passa a incluir "a comunidade formada por qualquer dos pais e seus descendentes", reconhecendo a existência de muitas possibilidades de arranjos familiares.

2 Seguido das leis especiais subsequentes em matéria de família (8.971/94 e 9.278/96 sobre união estável; Lei $8.069 / 98$ sobre a proteção das crianças e adolescentes; Lei 8.560/92 sobre reconhecimento de filhos fora do casamento) e especialmente o Novo Código Civil, que passou a vigorar em 10 de janeiro de 2003. 
Que fatos podem explicar mudanças tão radicais que afetam toda a concepção patriarcal de família da Igreja Católica e da moral ibérica? Ora, o direito é expressão das normas e valores sociais, como ensina Emile Durkheim. Vale dizer, as leis institucionalizam as normas sociais, que, por sua vez, dizem respeito às regras de convivência social existentes na prática, especialmente relacionadas entre as classes, entre os sexos e entre adultos e crianças .

\section{Recordando o passado}

Nos últimos 50 anos, um conjunto de circunstâncias relacionadas à crescente urbanização do país $e$ às profundas transformações da economia brasileira alterou usos e costumes, projetos de vida e valores. As regras morais eram ditadas pela Igreja Católica, que impunha seus preceitos através das escolas $e$ púlpitos. A moral sexual cristã impregnava todas aquelas instituições que deveriam ser laicas, tornando o catecismo matéria obrigatória, estigmatizando as mulheres que se separavam do marido e condenando a sexualidade desligada de fins reprodutivos.

A convivência entre meninos e meninas era dificultada pela prática das escolas católicas de dividir as turmas por sexo, segregando-as. Era mais um fator que reproduzia a educação de meninas reprimidas sexualmente, educadas para os afazeres domésticos, sem direito à educação formal e alijadas das carreiras profissionais de prestígio, como medicina, engenharia $e$ advocacia.

Com o avanço da industrialização $e$ a universalização do trabalho assalariado, uma série de transformações afetou as relações sociais e familiares. A rapidez das transformações econômicas provocou enorme impacto sobre o antigo modelo familiar, com um número de mulheres cada vez maior ingressando no mercado de trabalho. Aos poucos, as mulheres foram alcançando sua autonomia financeira, rompendo com um dos elos 
mais fortes do modelo tradicional de família: a subordinação econômica da esposa ao marido.

A presença crescente das mulheres nos locais de trabalhos $e$ nos transportes públicos aumentou o convívio entre os dois sexos nos espaços urbanos, diversificando o horizonte $e$ as perspectivas das mulheres. Através da democratização do acesso aos serviços públicos, com os concursos, as mulheres puderam ocupar postos com garantias de cumprimento das leis.

No começo do século XX as pessoas viviam em média 33 anos. Como as famílias eram numerosas, com cerca de seis filhos, o casamento constituía uma espécie de ocupação inexorável para as mulheres, cuja vida se consumia entre a maternidade e a casa. O modelo tradicional de família estava baseado numa divisão rígida de papéis: o homem era designado como "chefe da família" e a mulher, sua "principal auxiliar", estava em situação de inferioridade jurídica. Ao homem cabia zelar pelo sustento material da família, enquanto o cuidado com os filhos e os afazeres domésticos cabiam às mulheres.

Hoje, a esperança de vida mais do que dobrou e o novo padrão de família é bem menor, com cerca de 2 crianças por mulher em idade reprodutiva. A queda da taxa de fecundidade feminina implicou na diminuição do tamanho das famílias, acompanhando as tendências mundiais. Em todo o Brasil, o comportamento sócio-demográfico do conjunto da população apresenta as mesmas características de redução do tamanho da família, crescimento do número de famílias chefiadas por mulheres, novos arranjos familiares e envelhecimento da população. Ademais, duas descobertas científicas foram decisivas para a redefinição dos direitos sexuais da mulher.

A primeira delas é a pílula anticoncepcional que, não obstante os riscos que o uso prolongado pode acarretar, possibilitou um maior controle feminino sobre o uso de seu corpo. A partir de então, as mulheres puderem exercer sua sexualidade sem os riscos de uma gravidez indesejada. A pílula passou a ser vendida em escala industrial há 50 anos. 
A segunda delas é a descoberta do DNA, cujas repercussões sobre a vida das mulheres são ainda mais poderosas, pois incide também sobre direitos de filiação. Na verdade, o DNA foi descoberto há 57 anos, mas a criação do exame, que permite analisar o material genético das células, ocorreu há 25 anos. Segundo as leis brasileiras, no momento em que os homens não puderam mais contestar a paternidade após comprovação do DNA, acabou-se, também, o fardo que as mulheres carregaram historicamente de serem mães de filhos "sem pai", vale dizer, de filhos que levariam para o resto de suas vidas o estigma da ilegitimidade

Novas realidades implicam novas formas de pensar e novos valores com profundas repercussões sobre o estatuto das "famílias". Dado que os movimentos libertários de 68 y compris o feminismo foram críticos em relação à família autoritária $e$ patriarcal, vale a pena recordar as bandeiras então levantadas. ${ }^{3}$

\section{As várias dimensões do feminismo}

Defino feminismo como a manifestação política do mal estar das mulheres com as discriminações e desigualdades sociais que enfrentam pelo fato de serem "indivíduos do sexo feminino", tal como define o Dicionário Houaiss. Esse mal estar transformou-se em militância quando as mulheres conquistaram sua autonomia

${ }^{3}$ Não custa lembrar que o contexto político em que se desenvolveu o feminismo na Europa Ocidental, especialmente na França e na Itália, é radicalmente diferente dos sombrios anos das ditaduras militares no Cone Sul. Assim sendo, as propostas mais vanguardistas com respeito a "libertação sexual" e a abolição da família não aparecem nos manifestos feministas em nossas paragens, e, quando aparecem, são mais da autoria de grupos homossexuais, como o Lesbos Feminista, versão sexualidade hard em São Paulo e a versão do feminino cor-derosa, representado por Rosiska de Oliveira, no Rio de Janeiro.

Nos dias que correm, o apelo é justamente ter o direito a ter família e ser socialmente aceito. Foi-se o tempo em que as mulheres reivindicam o direito ao sexo sem procriação. Como bem observou Marylin Stratern (1995) a reivindicação atual é ter filhos sem necessariamente ter tido sexo. 
econômica, mesmo enfrentando discriminações nos locais de trabalho e menores salário, e com a democratização do ensino superior, que possibilitou a entrada de um contingente cada vez maior de mulheres nas universidades.

No Brasil, as lutas sociais foram criminalizadas com a ditadura militar que se iniciou em 1964 e que se notabilizou pelo emprego da tortura e da violência. Sindicatos, universidades e instituições suspeitas de oposição foram invadidos e cerceados. A imprensa e a mídia submetidas à censura política, a liberdade de organização foi vetada. Foram os anos de chumbo, que deixaram inúmeros mortos e desaparecidos entre os militantes da oposição.

$\mathrm{O}$ movimento feminista, desde seu início, aparece comprometido com a luta pelas "liberdades democráticas" e com a luta pela anistia. A declaração oficial da ONU, batizando 1975 como "Ano Internacional da Mulher", constitui uma referência fundamental para a compreensão do movimento de mulheres no Brasil até os dias de hoje. As comemorações do Ano Internacional da Mulher permitiram que as mulheres, principalmente nos Estados de São Paulo e do Rio de Janeiro, pudessem falar de seus problemas específicos e dar os primeiros passos no sentido de ampliar esse debate para outros setores sociais.

Por ocasião das primeiras eleições livres, em 1982, a oposição ganhou o governo do Estado de São Paulo e, pela primeira vez, foi criado o Conselho da Condição Feminina, que teve importante atuação na luta pelos direitos da mulher. Em 1985, foi criada, na cidade de São Paulo, a primeira Delegacia Especializada da Mulher. Uma das principais dificuldades da mulher vítima da violência masculina é ter de se submeter aos exames de corpo de delito e outros constrangimentos numa delegacia comum. Daí a importância histórica de tais delegacias, que se espalham aos poucos por todo o país. 


\section{Os novos direitos civis: a defesa dos direitos da mulher e da criança na família}

As sementes plantadas pelas feministas deixaram várias outras raízes, como se observa tanto no tocante à ampliação da oferta de creches, quanto nas importantes mudanças da legislação, incorporadas à Constituição de 1988, uma das mais avançadas do mundo. As mulheres passaram a ter os mesmos direitos que os homens no interior da família: igualdade jurídica dos cônjuges conforme artigo $225 \$ 5^{\circ}$; reconhecimento legal das uniões conjugais de fato e dos direitos da concubina.

Essas conquistas legais indicam como o lugar da mulher na família, no limiar dos anos noventa, difere radicalmente da subordinação da mulher ao homem estipulada pelas leis anteriores. Além de equiparar a mulher ao homem, com respeito ao poder familiar, as alterações legais foram de ordem a proteger ainda mais a maternidade, dando à mulher a responsabilidade da declaração do nome do pai. Tais conquistas, na verdade, têm um sentido social dos mais amplos ao garantir, prioritariamente, os direitos das crianças, como estabelece a Constituição de 1988, no seu artigo 227.

A questão da proteção à criança levanta problemas éticos e morais. Não basta a "judicialização" da infância e a declaração formal de seus direitos humanos. Dada sua vulnerabilidade, a posição jurídica da criança é muito especial. Não pode ser incluída em outros grupos sociais discriminados, pois sua condição é transitória: não há como confundi-la com discriminações baseadas em gênero ou etnia. O grande marco da questão no Brasil foi a promulgação do Estatuto da Criança e do Adolescente - ECA, pela Lei 8069, em 13 de julho de 1990. O ECA confirma a tese de que o

\footnotetext{
4 Um trabalho pioneiro sobre o tema foi publicado em 1999 pela Editora Revan, sob o título de A judicialização da política e das relações sociais no Brasil. O livro analisa os resultados de pesquisas realizadas por Luiz Werneck Vianna, Maria Alice Rezende de Carvalho, Manuel Palacios Cunha Melo e Marcelo Baumann Burgos.
} 
aprofundamento da democracia se dá pela extensão dos direitos a categorias especiais de cidadãos. A importância do ECA consiste em estabelecer esses parâmetros, assentado em dois pressupostos: a) as experiências da criança nos primeiros anos de vida são decisivas para seu desenvolvimento futuro, $e$ b) a criança não "conquista" seus direitos da mesma maneira que o adulto, pela simples razão de que depende do adulto (instituições ou família) para tanto.

Importa ressaltar que o ECA, considerado uma das mais avançadas legislações em escala mundial, foi conquistado pela perseverança de vários movimentos sociais, porta-vozes da pedagogia winicotiana. Segundo Donald Winnicott (1896-1971), é o amor daqueles que nos cuidam que alimenta em nós a possibilidade de amar e cuidar quando formos adultos:

Acho útil dividir o universo de pessoas em duas classes. Há aquelas que jamais se desapontaram enquanto bebês, e, na mesma medida, são candidatas a viver alegremente $e$ a aproveitar a vida. E há as que sofreram experiências traumáticas, provenientes de decepções com o ambiente, $e$ que necessitam carregar perpetuamente as lembranças (...) do estado em que se encontravam no momento do desastre (Winnicott, 1989:25).

Os cuidados com a infância não se restringem às bases de uma felicidade pessoal. A criança é um elemento estratégico no processo de reprodução de toda sociedade. É provável que dentre os princípios que compõem a concepção de "infância" nas mais variadas culturas, o único dado irredutível seja aquele que diz respeito à dependência da criança em relação aos seus maiores. Nada mais evidente, em vista da fragilidade biológica que nos cabe ao nascimento. Cada cultura tem um ideal de homem que orienta os valores e práticas socializadoras, definindo um padrão educacional. Para Emile Durkheim (1858-1917), educar "consiste na socialização metódica da jovem geração": 
o meio pelo qual a sociedade prepara no coração das crianças as condições essenciais de sua própria existência. Assim, a educação é a ação exercida pelas gerações adultas sobre aquelas que não estão ainda maduras para a vida. (Durkheim,1968:40)

Jean Piaget (1896-1980), ao longo de sua extensa obra, assentou as bases de uma pedagogia voltada para a cidadania democrática. Para ele, o princípio da submissão à autoridade (reflexo da dependência infantil aos mais velhos) deve ser gradativamente substituído pelo princípio da reciprocidade. Dessa maneira, a capacidade de altruísmo resulta do sentimento de gratidão próprio às crianças que se sentem queridas. Os cuidados parentais internalizados levam à responsabilidade individual pelo outro e ao seu reconhecimento como sujeito. A educação, nesse sentido, também possibilita a existência social. Crianças adequadamente cuidadas desenvolvem um sentimento de justiça intrínseco, daí o cuidado com a infância ser do interesse da coletividade democrática.

São esses os pressupostos ideológicos e teóricos do ECA que permitiram que os direitos das crianças não permanecessem no vasto e impreciso campo dos "direitos humanos" pois, como é óbvio, trata-se de um sujeito de direitos que não pode falar por si mesmo. Assim, na tentativa de ancorar a proteção à criança e ao adolescente em diretrizes mais sólidas, que pudessem ser efetivas em termos de suas necessidades específicas, o ECA constitui um avanço jurídico. ${ }^{5}$

\footnotetext{
5 Entretanto, no concernente à questão da adoção, o ECA preconiza a "adoção fechada", vale dizer, impede que a criança conheça suas origens, privando-a da verdade sobre sua própria história. A tese de mestrado de Maria Antonieta Pisano Motta (2005) analisa em profundidade o problema e foi publicada sob o título Mães abandonadas: a entrega de um filho em adoção.
} 
A nova família e a ordem jurídica

\section{Novos discursos sobre a família: o cuidar como princípio jurídico}

No final dos anos 70, Nancy Chodorow (1978) introduziu uma dimensão importante no debate feminista. A autora apontava a capacidade de maternar (mothering) como a mais importante distinção na educação de crianças do sexo masculino e feminino. Às meninas eram transmitidos os princípios do maternar - em outras palavras, de cuidar dos outros, como etapa preparatória de suas futuras funções maternas.

Não obstante a existência de vários feminismos e de que a questão da maternidade era um dos divisores de água (execrada por Simone de Beauvoir, por exemplo), a dimensão do cuidar passou a figurar nas análises, até mesmo para ser monetariamente contabilizada, pois se tratava de uma das parcelas mais significativas do "trabalho invisivel" exercido pelas mulheres.

Muitos anos se passaram e, das diversas frentes de luta do feminismo, a questão do reconhecimento do cuidar constitui a mais evidente vitória. Quer seja amparado pelo ECA de 1990, quer seja no Estatuto do Idoso de 2003, o princípio da solidariedade e do cuidar encontram respaldo jurídico. Essa valorização do cuidar reflete-se na própria definição atual de família, na medida em que "é família quem cuida". A jurisprudência brasileira acolhe tanto o princípio do "cuidar" como o da "solidariedade" e da "responsabilidade".

Assim, uma das características da nova familia é justamente a mudança de pressupostos. Não se trata mais de uma instituição nascida do casamento legal heterossexual e sim da disposição em cuidar de outrem (criança ou idoso, mais vulnerável por definição).

Da mesma maneira, é interessante observar o fortalecimento da "família" como instituição fundamental de nossa sociedade, tal como pude constatar pela leitura de vários acórdãos, reforçados pelas declarações de Giselle Groeninga (2008), psicóloga e psicanalista, diretora de Relações Interdisciplinares do Instituto 
Brasileiro de Direito da Família - IBDFAM e uma das teóricas mais ativas no campo do Direito de Família. ${ }^{6}$ Um exemplo de jurisprudência inovadora foi estudado por Janaina Rosa Guimarães (2008), advogada e pesquisadora, "que analisaa uma série de acórdãos que equiparam as mães de criação às mães biológicas e os filhos de criação aos filhos adotivos, concedendo direitos iguais na pensão e nos bens. Essa jurisprudência está em consonância com o direito italiano, espanhol e português, mas avança muito em relação ao código brasileiro. Daí sua conclusão de que muitas dessas decisões favoráveis ao vínculo sócio-afetivo em detrimento da relação sanguínea implicam no reconhecimento de "a posse de estado de filho" e estão, na verdade, "à margem da lei". No entanto, constituem decisões de vanguarda por "reconhecerem nas famílias unidas pelos laços de amor e de gratidão uma relação afetiva, íntima e duradoura. É a verdade sócio-afetiva ganhando abrigo do Direito" (Guimarães, 2008: pp.??), como conclui o artigo. ${ }^{7}$

\section{Avanços e recuos: limites dos "direitos reprodutivos"}

Em contrapartida, as forças mais conservadoras da sociedade, especialmente representadas pelas diversas igrejas, utilizam o mesmo conceito de respeito aos direitos humanos para

6 A família não mais pode ser pensada de forma dividida, ela é um sistema em que os integrantes exercem funções complementares. Da mesma forma, há uma confusão na divisão que se faz ao falar do superior interesse da criança e do adolescente como se fosse contrário ao dos pais. O que existe é, na realidade, o superior interesse da família, sendo que como sua função primordial é a do atendimento e cuidado de seus membros, priorizando-se o grau de fragilidade de cada um, o interesse da criança traduz, assim, a finalidade primeira da família.

7 Tal como pude constatar pelos levantamentos prévios, os tribunais do Rio Grande do Sul são os mais abertos às inovações e os mais avançados na jurisprudência da família. Entre as juízas, destaca-se Nanci Andrighi, e entre as advogadas, Maria Berenice Dias, atual presidenta do IBDFAM, cujo VII Congresso (28 a 31 de outubro de 2009) teve como tema "família e responsabilidade". 
atacar a legalização do aborto. Assim, por iniciativa da Igreja Católica, circula hoje o Congresso Nacional a proposição que institui o "direito do nascituro". Também no que concerne aos direitos de adoção e legalização das relações homo-afetivos temos a mesma divisão entre grupos de pressão conservadores e os inovadores ou vanguardistas.

Nesse sentido, há que lamentar a ausência de valores republicanos e laicos, apesar da separação formal entre Estados e Igrejas. O fato de que as lutas políticas assumam, hoje, também a forma de lutas religiosas tem como pressuposto a inexistência de sistemas morais alternativos aos religiosos. Assim, permanecemos na esfera do pecado, dos crimes cometidos contra a vontade divina. A instituição religiosa continua sendo a matriz da moralidade pública. Nesse contexto, não há que se estranhar o interdito da legalização do aborto em toda a América Latina, com exceção de Cuba e, muito recentemente, o Uruguai.

$\mathrm{Na}$ Itália, nos anos 1970, a esquerda uniu-se, apoiou as feministas, enfrentou o Papa e venceu. Divórcio e aborto foram legalizados. No Brasil, foi necessário que um ditador protestante, o general Geisel, que não suportava a Igreja Católica, impusesse o divórcio, em 1977. Mas permanecem as restrições legais ao aborto, ao mesmo tempo em que prosperam a indústria de aborto clandestino e todo o ciclo de corrupção: policiais que fecham os olhos para as clínicas de aborto de quem pode pagar e mulheres pobres que arriscam a vida na mão de aborteiros sem formação médica. E aqui temos o círculo vicioso: as igrejas são as fontes de moral face ao abandono do Estado; e as igrejas são contra o aborto, que as mulheres pobres fazem em piores condições $e$ ainda pedem perdão ao padre. Nesse sentido, é necessário questionar o fiasco brasileiro em enfrentar o poder da Igreja e ressaltar a importância das virtudes republicanas, do sentido da coisa pública. 


\section{A família é então uma instituição perene?}

Retomando nosso tema, talvez a mais apropriada explicação para a permanência da família, que não é mais aquela dos anos 50 - o triunfante modelo nuclear, mamãe dona de casa e papai provedor -, esteja na seguinte constatação da filósofa Veronique Munoz-Dardé (2001:322) no texto que recebeu o sugestivo título Devemos abolir a família?

A família parece ser uma instituição imutável

porque ela se modifica constantemente. Contrariamente ao que se supõe comumente, é a instabilidade da compreensão social do que constitui uma família adequada e quais seriam as relações familiares convenientes, o que permitiu a sobrevivência ao longo do tempo da família com instituição forte e simbolicamente rica.

Retornemos às novas famílias $e$ no que alteram substancialmente as atuais regras do jogo. Do ponto de vista jurídico, a fórmula encontrada pelos franceses com sua "união cível" possibilita qualquer tipo de arranjo familiar com direitos à herança, etc., sem que seja necessário reconhecer explicitamente a orientação sexual dos parceiros. Mas as diferentes técnicas reprodutivas, envolvendo a barriga de aluguel $e$ a inseminação artificial, provocam alterações substanciais, pois o nascimento biológico não mais enquadra o social da aliança, como observa a etnóloga Anne Condorcet (2002:265).

Sim, o parentesco pode não ser mais a junção de laços de sangue com laços de afinidade e, em definitivo, tornar-se apenas um laço de afinidade, uma escolha pessoal. Segundo Lévi-Strauss (apud Parseval, 2001), as escolhas da sociedade não pertencem aos sábios, mas aos cidadãos.

Não custa recordar que nosso pai fundador Emile Durkheim apontou o individualismo como uma característica marcante dos tempos modernos $e$, contra a tendência à autonomização crescente da sociedade, acreditou ser a instituição familiar a 
A nova família e a ordem jurídica

melhor contrapartida. Razão pela qual, não obstante seu republicanismo, foi contra a possibilidade do divórcio amigável.

Mais recentemente, Ulrich Beck (2001:44) também acentuou a autonomia e o individualismo crescentes como próprios da contemporaneidade, e concluiu que o amor constitui "a melhor ideologia contra os perigos da individualização" porque promete aos "indivíduos singulares reencontrar uma dimensão de comunidade". 8 Sigmund Freud (1973:3043) ${ }^{9}$ e Max Weber (1963) discordariam dessa tese. Para ambos, o amor, especialmente o amor sexual, é anti-social, pois exclui os demais da comunidade formada pelo par enamorado. Ademais, é essa dimensão subversiva que origina as várias formas de controle social. Ao analisar a ética da fraternidade das religiões de salvação e a esfera do erótico, Weber refere-se à profunda tensão existente entre tais religióes e a "maior força irracional da vida: o amor sexual" (id.ib.:398).

A proposição de Beck pode também ser tomada como uma provocação, como a demonstração de que num mundo em que a esfera política foi esvaziada de projetos de transformação, a alternativa da comunidade limita-se ao amor entre duas pessoas. A ideologia do amor, bem como a ideologia da família, ilumina o

8 Pour cet ensemble des raisons, l'amour constitue en tout cas contre les périls de l'individualisation la meilleure idólogie qui soit. S'il met l'accent sur la singularité , il promet cependant à tous ces individus singuliers de retrouver une dimension de communauté, non par un retour a des traditons permanentes ni a la faveur de considerations économiques ou légales, mais seulement pra la vertu des sentiments vrais et imméditate, grâce à la croyance des individus dans l'amour, et la façon dont, a chaque fois, elle se trouve a incarner dans uns persone. Les instances de l'amour sont les individuas isolés, qui par la simple force de leu enthousiasme s'arogent l'un a l'autre leur droit de cree leur propre droit (Beck, 2001:44).

9 "al derivar la antitesis entre la cultura y la sociedad del hecho de que el amor sexual constituye una relación entre dois personas, en las que un tercero sólo puede desempenãr un papel superfluo o pertubador, mientras que, por el contrariom, la cultura implica necessariamente relaciones entre mayor número de personas" (Freud, 1973:3043). 
lado harmonioso e aconchegante das relações pessoais. A questão que se coloca é por que tais valores e ideologias começam a ser normatizados, vale dizer, por que passam a ser da competência da justiça? A tendência crescente à "judicialização" da esfera privada não estaria a indicar que é preciso garantir pela lei aquilo que a ideologia da família e do amor não garante na prática?

\section{Referências bibliográficas}

AzAmbujA, Maria Regina Fay de, SilveirA, Maritana Viana e BRUNO Denise. Infância em Família: Um compromisso de todos Duarte. São Paulo, Del Rey Editora, 2004.

BowlBY, John. Cuidados Maternos e Saúde Mental. 2a ed. São Paulo, Martins Fontes, 1988.

CHODOROW, Nancy. The reproduction of mothering. Beverly, The University of California Press, 1978.

CONDORCET, Anne. Le bricolage de la parenté. Paris, Editions Odile Jacob, 2002.

DEBERT, Guita Grin et alii. Gênero, família e gerações: Juizado Especial Criminal e Tribunal do Júri. Campinas-SP, Núcleo de Estudos de Gênero-Pagu/Unicamp, 2008 [Coleção Encontros].

DIAS, Maria Berenice. Manual de direito das famílias. $4^{\mathrm{a}}$ ed. rev., atual. e ampl. São Paulo, RT, 2007a.

.Conversando sobre alimentos. São Paulo, Livraria do Advogado, 2007b.

. Incesto e Alienação Parental. São Paulo, Livraria do Advogado, 2007c.

. e PeREIRA, Rodrigo da Cunha. Direito de Família e o novo Código Civil. São Paulo, Del Rey, 2006.

DURKHEIM, Emile. Education et Sociologie. Paris, Presses Universitaires de France, 1968.

. Le divorce par consentement mutuel. Dans le cadre de la collection: Les classiques des sciences sociales, 1906 
A nova família e a ordem jurídica

[http://www.uqac.uquebec.ca/zone30/Classiques_des_sciences_sociale s/index.html].

FREUD, Sigmund. EL Malestar de la Cultura. In: Obras, tomo. 3. Madrid, Bibioteca Nueva, 1973 [Tradução: Luiz L.Ballesteros].

GIORGIS, José Carlos Teixeira. Paternidade fragmentada. São Paulo, Saraiva/Livraria do Advogado, 2007.

GUIMARÃES, Janaina Rosa. Filho de criação - 0 valor jurídico do afeto a Entidade Familiar. IBDFAM, 10/06/2008.

IBDFAM. Entrevista com Giselle Groeninga - Direito à Família. Boletim, ed. $51,11 / 08 / 2008$.

MoraES, Maria Lygia Quartim de. Infância e Cidadania. Cadernos de Pesquisa, no 91, São Paulo, Fundação Carlos Chagas, 1994, pp.2330.

MotTA, Maria Antonieta Pisano. Mães abandonadas: a entrega de um filho em adoção. $2^{\text {a } e d ., ~ S a ̃ o ~ P a u l o, ~ C o r t e z, ~} 2005$.

MUNOZ-DARDÉ, Veronique. Doit-on alors abolir la famille? Revue de philosophie et sciences sociales, $n^{\circ}$ 2, Paris, PUF, 2001.

Oro, Ari Pedro, Dias, Maria Berenice, Blancarte, Roberto. Em Defesa Das Liberdades Laicas. São Paulo, Livraria dos Advogados/Saraiva, 2008.

PARSEVAL, Genevieve Delaisi. La parentalité est-elle divisible? Comprendre, $\mathrm{n}^{\circ}$ 2. Paris, PUF, 2001.

Pereira, Rodrigo da Cunha. Afeto, ética, família e o Novo Código Civil. São Paulo, Del Rey, 2004.

e CAHALI, Francisco da Cunha. Alimento no Código Civil. São Paulo, Saraiva, 2005.

PIAGET, Jean. O julgamento moral na criança. São Paulo, Editora Mestre Jou, 1977.

PIOVESAN, Flávia. Direitos Humanos e Globalização. In: Direito Global São Paulo, Max Limonad, 1998. 
ROUDINESCO, Elizabeth. A família em desordem. Rio de Janeiro, Jorge Zahar Editor, 2003.

SouZA, Ivone Coelho de. (org.) Direito de Família: Diversidade e Multidisciplinaridade. Rio Grande do Sul, Editora IBDFAM/RS, 2009. . Direito de Família e Diversidade e Multidisciplinaridade. Rio Grande do Sul, Editora IBDFAM/RS, 2007.

STRATERN, Marylin. Necessidade de pais, necessidade de mães. Estudos Feministas, vol. 3, n 2, Rio de Janeiro, 1995, pp.303-329.

WeBER, Max. Ensaios de Sociologia. In: GerTh, H.H. e MiLls, Wrighy. (orgs.) Rio de Janeiro, Zahar Editores, 1963.

WinnicotT, D.W. Tudo Começa em Casa. São Paulo, Martins Fontes, 1989. . Privação e Delinquência. São Paulo, Martins Fontes, 1987. 